\title{
Off-pump versus on-pump myocardial revascularization in patients with ST-segment elevation myocardial infarction: A randomized trial
}

Khalil Fattouch, MD, PhD, Francesco Guccione, MD, Pietro Dioguardi, MD, Roberta Sampognaro, MD, Egle Corrado, MD, Marco Caruso, MD, and Giovanni Ruvolo, MD

\begin{abstract}
Objective: Conventional cardioplegic arrest coronary artery bypass grafting after ST-segment elevation myocardial infarction is associated with high mortality and morbidity. The benefits of off-pump surgery have been suggested. This study randomly evaluated the impact of the off-pump technique on clinical results.
\end{abstract}

\begin{abstract}
Methods: Between February 2002 and October 2007, 128 patients with ST-segment elevation myocardial infarction who underwent myocardial revascularization within 48 hours from the onset of symptoms were randomly assigned to 2 groups: on-pump group ( 66 patients/51.5\%) and off-pump group (63 patients/48.5\%). The primary end point was the incidence of in-hospital death and outcomes (low cardiac output syndrome, prolonged mechanical and pharmacologic cardiac support, prolonged mechanical ventilation support, and postoperative length of stay in intensive care unit and hospital). The secondary end point was the evaluation of myocardial infarct size measured by the perioperative serum release of cardiac troponin I and the improvement of contractile cardiac function evaluated by the wall motion score index.
\end{abstract}

Results: Overall in-hospital mortality was $4.6 \%$. In-hospital mortality was $7.7 \%$ (5 patients) in the on-pump group and $1.6 \%$ (1 patient) in the off-pump group $(P=.04)$. Statistically significant differences were found between the 2 groups concerning the incidence of low cardiac output syndrome $(P=.001)$, time of inotrope drugs support $(P=.001)$, time of mechanical ventilation $(P=.006)$, reoperation for bleeding $(P=.04)$, intensive care unit stay $(P=.01)$, and in-hospital stay $(P=.02)$. Statistically significant differences also were found between the 2 groups concerning the incidence of in-hospital death in patients who were admitted to surgery in cardiac shock $(P=.0018)$ and patients who underwent surgery within 6 hours from the onset of symptoms $(P=$ $.0026)$. The procedure in 1 patient $(1.6 \%)$ in the off-pump group was converted to the on-pump beating heart technique. The serum levels of cardiac troponin I were high in the on-pump group during the first 48 hours after surgery. Myocardial function was better in the off-pump group. There were no cardiac-related late deaths, and patients had no recurrent cardiac events.

Conclusion: Off-pump surgery reduced early mortality and morbidity in patients with ST-segment elevation myocardial infarction in respect to the conventional procedure. Off-pump surgery showed better results than on-pump surgery in patients who underwent surgery within 6 hours from the onset of symptoms and in patients with cardiogenic shock.

Despite more than 30 years of experience with coronary artery bypass grafting (CABG), controversy still exists on the optimal timing of surgical revascularization after acute myocardial infarction (AMI). Systemic fibrinolytic treatment and primary percutaneous coronary intervention (PCI) are both effective and represent the first-choice treatment for acute ST-segment elevation myocardial infarction (STEMI), although several randomized studies have shown that primary PCI is superior to thrombolytic therapy in achieving early reperfusion and reducing mortality. ${ }^{1-3}$ In the last 2 decades, $\mathrm{CABG}$ in the presence of or immediately after AMI has

From the Unit of Cardiac Surgery, University of Palermo, Palermo, Italy.

Received for publication May 2, 2008; revisions received Sept 3, 2008; accepted for publication Nov 17, 2008.

Address for reprints: Khalil Fattouch, MD, PhD, University of Palermo, Cardiac Surgery Department, Via Liborio Giuffré 5, 90127, Palermo (E-mail: khalilfattouch@ hotmail.com).

J Thorac Cardiovasc Surg 2009;137:650-7

$0022-5223 / \$ 36.00$

Copyright (c) 2009 by The American Association for Thoracic Surgery doi: $10.1016 /$ j.jtcvs.2008.11.033 been controversial because the mortality and morbidity rates were high ${ }^{4-7}$ and it was performed primarily in patients with mechanical complications of AMI or refractory cardiogenic shock.

Emergency CABG in patients with STEMI is still associated with high mortality and morbidity, and the early outcome is poor compared with the outcome in patients with stable angina. Furthermore, it may be advisable to delay surgery whenever possible. However, in patients with STEMI, emergency surgery within the first hours is indicated. ${ }^{8} \mathrm{Cur}-$ rent indications for emergency $\mathrm{CABG}$ in patients with STEMI are limited to those presenting with evolving myocardial ischemia refractory to optimal medical therapy, presence of left main stenosis or 3-vessel disease, ongoing ischemia despite successful or failed PCI, complicated PCI, or cardiogenic shock accompanied by complex coronary anatomy. Operative mortality for these patients using conventional arrested-heart CABG techniques ranges from $1.6 \%$ to $32 \%$ and strongly depends on the preoperative hemodynamic condition. . $^{-7,9-11}$ 

Abbreviations and Acronyms
AMI = acute myocardial infarction
$\mathrm{CABG}=$ coronary artery bypass grafting
$\mathrm{CPB}=$ cardiopulmonary bypass
$\mathrm{cTnI}=$ cardiac troponin I
ICU = intensive care unit
IVP $=$ interventricular posterior artery
LAD $=$ left anterior descending artery
LCOS = low cardiac output syndrome
LITA $=$ left internal thoracic artery
PCI = percutaneous coronary intervention
STEMI $=$ ST-segment elevation myocardial infarction

The use of off-pump strategies for CABG is being intensively debated at present. Several retrospective studies have suggested the benefits of off-pump surgery on in-hospital mortality and postoperative outcomes. ${ }^{12-16}$ This study randomly evaluated the impact of off-pump versus on-pump CABG on early and midterm results in patients with STEMI who underwent urgent CABG.

\section{PATIENTS AND METHODS}

\section{Patients, Study Design, and Protocol}

Between February 2002 and October 2007, 152 patients with STEMI who were admitted to the University of Palermo Cardiac Surgery Department to undergo an urgent CABG were consecutively and prospectively screened for this study. Patients were referred to the Cardiac Surgery Department from 7 hemodynamic laboratories and 12 coronary intensive care units (ICUs) in the West Sicily district, Italy (Sicilian Network for surgical treatment of patients with STEMI). Fibrinolytic or PCI therapy was applied or considered as first-choice treatment in all patients at the first ICU admission before enrollment to undergo CABG.

Indications for surgery were recurrent myocardial ischemia refractory to medical therapy in patients with a) a significant area of myocardium at risk who were not candidates for fibrinolytic or primary PCI therapy; b) coronary lesions unsuitable for primary PCI and hemodynamic instability or angina; with primary PCI failure and persistent symptoms or hemodynamic instability; c) life-threatening ventricular arrhythmia and left main stenosis or 3-vessel disease; d) multivessel or left main disease and hemodynamic instability; or e) cardiogenic shock after AMI.

Exclusion criteria were a) mechanical complications of myocardial infarction; b) cardiopulmonary resuscitation required before surgery; c) lifesaving procedures; d) onset of cardiac shock in more than 24 hours; e) ischemic mitral valve regurgitation more than moderate; and f) concomitant cardiac surgical procedures, such as left ventricular aneurysm and mitral valve repair.

Twenty-four patients were excluded, and 128 patients were eligible for enrollment in this study.

The diagnosis of AMI was based on clinical criteria, including electrocardiographic signs (Q waves and ST-segment elevation) and increase in serum myocardial enzymes levels (creatine phosphokinase and cardiac troponin I [cTnI]). The criteria for preoperative insertion of an intraaortic balloon pump were as follows: refractory left ventricular failure, hemodynamic instability despite catecholamine administration, refractory angina or intractable life-threatening ventricular arrhythmias, and cardiogenic
TABLE 1. Preoperative demographics and clinical characteristics

\begin{tabular}{lccc}
\hline \multicolumn{1}{c}{ Variables } & $\begin{array}{c}\text { On-pump 65 } \\
\text { patients (\%) }\end{array}$ & $\begin{array}{c}\text { Off-pump 63 } \\
\text { patients (\%) }\end{array}$ & $\begin{array}{c}\boldsymbol{P} \\
\text { value }\end{array}$ \\
\hline Age (mean \pm SD) & $61 \pm 18$ & $63 \pm 16$ & .68 \\
Age > 70 y & $13(21 \%)$ & $15(24 \%)$ & .38 \\
Sex (male) & $50(77 \%)$ & $38(61 \%)$ & .05 \\
Diabetes mellitus & $26(41 \%)$ & $24(39 \%)$ & .42 \\
Hypertension & $44(68 \%)$ & $38(61 \%)$ & .47 \\
Smoking & $43(66 \%)$ & $32(52 \%)$ & .07 \\
COPD & $7(11 \%)$ & $6(9.5 \%)$ & .72 \\
Left main stenosis $>50 \%$ & $15(23 \%)$ & $12(19 \%)$ & .52 \\
Cardiogenic shock & $11(17 \%)$ & $13(22 \%)$ & .43 \\
Old MI & $12(19 \%)$ & $24(39 \%)$ & .02 \\
Mean LVEF \% & $42 \pm 12$ & $44 \pm 10$ & .71 \\
Type of AMI: & & & \\
Anterior & $45(70 \%)$ & $41(65 \%)$ & .36 \\
Inferior & $20(30 \%)$ & $22(35.5 \%)$ & .38 \\
Ejection fraction $<35 \%$ & $10(15 \%)$ & $8(13 \%)$ & .72 \\
Life-threatening arrhythmias & $8(12 \%)$ & $6(9.5 \%)$ & .51 \\
Timing of surgery: & & & \\
$\quad<6$ h & $13(20 \%)$ & $13(22 \%)$ & .68 \\
6-24 & $21(32 \%)$ & $30(48 \%)$ & .07 \\
24-48 h & $31(48 \%)$ & $20(32 \%)$ & .06 \\
Preoperative IABP & $18(28 \%)$ & $20(32 \%)$ & .82 \\
Fibrinolytic therapy & $14(21.5 \%)$ & $13(22 \%)$ & .91 \\
PCI failure & $11(17 \%)$ & $12(19 \%)$ & .68 \\
Enzymatic profile & & & \\
CK-MB (ng/mL) & $155 \pm 26$ & $158 \pm 22$ & .81 \\
cTnI (ng/mL) & $31 \pm 18$ & $29 \pm 15$ & .78 \\
Myoglobin (ng/mL) & $1920 \pm 510$ & $1875 \pm 385$ & .63 \\
GOT (U/L) & $115 \pm 28$ & $102 \pm 32$ & .58 \\
GPT (U/L) & $64 \pm 18$ & $66 \pm 20$ & .62 \\
\hline COPD, Cho) \\
(15)
\end{tabular}

COPD, Chronic obstructive pulmonary disease; $M I$, myocardial infarction; $A M I$, acute myocardial infarction; $L V E F$, left ventricular myocardial infarction; $I A B P$, intraaortic balloon pump; $P C I$, percutaneous coronary intervention; $C K-M B$, creatine kinase myocardial band isoenzyme; $c T n I$, cardiac troponin I; GOT, glutamic-oxaloacetic transaminase; $G P T$, glutamic-pyruvic transaminase; $S D$, standard deviation. Data are presented as mean $\pm \mathrm{SD}$, or number $(\%)$.

shock defined as a systolic blood pressure of less than $80 \mathrm{~mm} \mathrm{Hg}$, as well as clinical signs of hypoperfusion. All patients underwent surgery within 48 hours from the onset of symptoms by 2 dedicated surgical team with a high level of experience in off-pump and on-pump CABG.

Patients were prospectively randomized into 2 groups by card allocation: on-pump group (65 patients/51\%) or off-pump group (63 patients/ $49 \%$ ). Randomization was blended for ICU and postoperative care staff, including nurses, anesthetists, and cardiologists. This study was also blended for the cardiologist who performed the clinical follow-up. The study was approved by the institutional review board of the University of Palermo. Each patient signed an informed consent form. Preoperative demographic and clinical characteristic of patients are illustrated in Table 1.

\section{Clinical Study End Points}

The primary end point of the study was the incidence of in-hospital death and outcome of postoperative major adverse events, such as the incidence of low cardiac output syndrome (LCOS), life-threatening arrhythmias of prolonged mechanical and pharmacologic cardiac support, prolonged mechanical ventilation support ( $>48$ hours), and postoperative length of stay in the ICU and in hospital. 
The secondary end point of the study was the evaluation of myocardial infarct size or the extent of irreversible myocardial cell injury, as measured by the perioperative serum release of $\mathrm{cTnI}$ and the improvement of contractile cardiac function evaluated by transesophageal echocardiography.

\section{Surgical Technique and Management}

Standard anesthesia was induced with fentanyl $(20-50 \mu \mathrm{g} / \mathrm{kg})$, midazolam $(0.1 \mathrm{mg} / \mathrm{kg})$, and pancuronium bromide $(0.1 \mathrm{mg} / \mathrm{kg})$, and maintained with a continuous infusion of fentanyl $(0.5-1 \mu \mathrm{g} / \mathrm{kg} / \mathrm{h})$ and propofol $(50-200 \mu \mathrm{g} / \mathrm{kg} / \mathrm{h})$.

On-pump CABG. CABG was performed using cardiopulmonary bypass $(\mathrm{CPB})$ performed under moderate systemic hypothermia $\left(32^{\circ} \mathrm{C}\right)$, keeping a continuous flow at 2 to $2.5 \mathrm{~mL} / \mathrm{min} / \mathrm{m}^{2}$ and perfusion pressure between 50 and $80 \mathrm{~mm} \mathrm{Hg}$. Myocardial protection was achieved with intermittent antegrade warm-blood cardioplegia. When the hemodynamic condition was stable, the left internal thoracic artery (LITA) was harvested and used as in situ graft to the left anterior descending (LAD) coronary artery. Myocardial revascularization was completed using saphenous vein grafts in all patients. All distal anastomoses were performed during a single aortic crossclamp period. The time sequence of coronary revascularization was first the right coronary or interventricular posterior (IVP) artery, followed by the marginal obtuse artery, and finally by the LAD artery. During aortic crossclamp time, cardioplegia solution was infused anterogradely through the ascending aorta and into the venous grafts. The proximal anastomoses of the grafts were performed with tangential clamping of the ascending aorta during the reperfusion phase.

Off-pump CABG. CABG was performed using a commercially available mechanical stabilizer (Octopus, Medtronic Inc, Minneapolis, Minn). An apical suction cardiac positioning device (Starfish, Medtronic Inc) was used in revascularization of the circumflex branch. A right ventricle anterior wall suction, next to the acute margin of the heart, was applied during revascularization of the interventricular posterior coronary artery to facilitate exposure and to avoid severe right ventricle dysfunction. Intracoronary shunts were used for all anastomoses (Clearview, Medtronic Inc). Temporary proximal occlusion of the target vessel was performed using 50 polypropylene sutures with Teflon pledgets. The first anastomosis was routinely performed between the LITA and the LAD, but the right coronary or IVP artery was grafted first in patients with inferior AMI who underwent surgery within 12 hours from onset of symptoms. The second anastomosis was performed between the saphenous vein graft and the IVP artery and finally to the marginal obtuse artery.

After implantation of all grafts, the mean graft flow was assessed by Doppler transit time flowmetry for each conduit using a Transonic Systems Inc Flowmeter (Ithaca, NY). Postoperative ICU management was standardized for all patients and blended for physicians and nurses. All patients underwent intraoperative and postoperative hemodynamics monitoring by a 12-lead electrocardiogram and invasive radial artery.

\section{Myocardial Regional Wall Motion Analysis}

Intraoperative transesophageal echocardiographic control was performed in all patients to evaluate global and regional myocardial function. A 2-dimensional cardiac ultrasound from Hewlett Packard (Sonos 4500, Palo Alto, Calif) equipped with a transesophageal echocardiographic probe was used. Myocardial kinesia was evaluated in according to the guidelines of the American Society of Echocardiography. ${ }^{17}$

\section{Blood Samples}

Serum creatine kinase myocardial band isoenzyme and cTnI levels were measured preoperatively, during, and after surgery, at 6 different times: $\mathrm{T} 1=$ preoperatively; $\mathrm{T} 2=$ at 1 hour, $\mathrm{T} 3=$ at 6 hours, $\mathrm{T} 4=$ at 12 hours, $\mathrm{T} 5=$ at 24 hours, and $\mathrm{T} 6=$ at 48 hours postmyocardial revascularization.

\section{Statistical Analyses}

Numeric values were expressed as mean \pm standard deviation. Continuous variables were compared between groups using the Student unpaired $t$ test. The frequency ratios between groups were compared using the chisquare test. For repeated measures of cTnI at different times, analysis of variance with the multiple comparison method (Student-Newman-Keuls test) was used. The Statistical Package for the Social Sciences software (SPSS Inc, Chicago, Ill) was used.

\section{RESULTS}

Demographic characteristics and intraoperative and postoperative data are summarized in Tables 1 and 2. The 2 groups did not differ in age, type of AMI, incidence of thrombolysis or primary PCI treatment, shock, and timing of surgery. There were statistically significant differences between the 2 groups in gender $(P=.04)$ and incidence of previous myocardial infarction $(P=.02)$.

Complete myocardial revascularization was performed in all patients with success, and no differences were observed between the groups in the mean number of grafts per patient, number of LITA grafts used, and mean value of grafts flow. The procedure in 1 patient $(1.6 \%)$ in the off-pump group was converted to on-pump beating heart surgery, which was performed with success.

\section{Early Mortality and Outcomes}

The overall in-hospital mortality rate was $4.7 \%$ (6 patients) (Table 3). Five patients (7.7\%) died in the on-pump

TABLE 2. Intraoperative data and postoperative outcomes

\begin{tabular}{|c|c|c|c|}
\hline Variables & $\begin{array}{l}\text { On-pump } 65 \\
\text { patients }(\%)\end{array}$ & $\begin{array}{l}\text { Off-pump } 63 \\
\text { patients }(\%)\end{array}$ & $\begin{array}{c}P \\
\text { value }\end{array}$ \\
\hline Grafts/patient & $2.8 \pm 0.4$ & $2.6 \pm 0.5$ & .68 \\
\hline Use of catecholamines ${ }^{\mathrm{a}}$ & $22(34 \%)$ & $13(21 \%)$ & .02 \\
\hline Time of inotrope support (d) & $6.8 \pm 2.4$ & $2.1 \pm 1.4$ & .001 \\
\hline LITA graft & $60(92 \%)$ & $59(93.6 \%)$ & .82 \\
\hline IABP support & $20(31 \%)$ & $20(32 \%)$ & .86 \\
\hline Time of IABP use (d) & $3.6 \pm 2.4$ & $1.9 \pm 0.4$ & .06 \\
\hline \multicolumn{4}{|l|}{ Grafts flow $(\mathrm{mL} / \mathrm{min})$ : } \\
\hline LITA to IVA & $25 \pm 11$ & $25 \pm 8$ & .91 \\
\hline SVG to MO & $35 \pm 18$ & $38 \pm 12$ & .64 \\
\hline SVG to IVP & $38 \pm 12$ & $40 \pm 9$ & .71 \\
\hline \multicolumn{4}{|l|}{ Complications } \\
\hline LCOS & $8(12 \%)$ & $2(3 \%)$ & .001 \\
\hline Renal failure & $4(6 \%)$ & $3(4.8 \%)$ & .43 \\
\hline Tracheostomy & $2(3 \%)$ & $1(1.6 \%)$ & .12 \\
\hline MOF & $2(3 \%)$ & & \\
\hline Reoperation for bleeding & $5(7.7 \%)$ & $1(1.6 \%)$ & .04 \\
\hline Sepsis & $1(1.5 \%)$ & & \\
\hline Hospital stay (d) & $12.4 \pm 5.7$ & $8.3 \pm 1.7$ & .02 \\
\hline ICU stay (d) & $3.4 \pm 2.1$ & $1.6 \pm 0.7$ & .01 \\
\hline Mechanical ventilation (h) & $24 \pm 12.7$ & $8.5 \pm 3.7$ & .006 \\
\hline
\end{tabular}

LITA, Left internal thoracic artery; IABP, intraaortic balloon pump; IVA, interventricular anterior artery; $S V G$, saphenous vein graft; $M O$, obtuse marginal ramus; IVP, interventricular posterior artery; $L C O S$, low cardiac output syndrome; $M O F$, multiorgan failure; $I C U$, intensive care unit. Data are presented as mean $\pm \mathrm{SD}$, or number $(\%)$. ${ }^{a}$ Dopamine or dobutamine $>6 \mu \mathrm{g} / \mathrm{kg} / \mathrm{min}$, adrenaline $>0.08 \mu \mathrm{g} / \mathrm{kg} / \mathrm{min}$. 
TABLE 3. In-hospital death

\begin{tabular}{lccc}
\hline \multicolumn{1}{c}{ Variables } & $\begin{array}{c}\text { On-pump 65 } \\
\text { patients (\%) }\end{array}$ & $\begin{array}{l}\text { Off-pump 63 } \\
\text { patients (\%) }\end{array}$ & \multicolumn{1}{c}{$\boldsymbol{P}$ value } \\
\hline Total & $5(7.7 \%)$ & $1(1.6 \%)$ & .04 \\
Cardiac shock & $3 / 11(27 \%)$ & $1 / 13(7.5 \%)$ & .0018 \\
No cardiac shock & $2 / 54(3.7 \%)$ & $0 / 49(0 \%)$ & \\
Timing $<6 \mathrm{~h}^{\mathrm{a}}$ & $3 / 13(23 \%)$ & $1 / 13(7.5 \%)$ & .0026 \\
Timing 6-48 $\mathrm{h}$ & $2 / 52(3.8 \%)$ & $0 / 49(0 \%)$ & \\
\hline
\end{tabular}

${ }^{\mathrm{a}}$ From onset of symptoms.

group, and 1 patient died $(1.6 \%)$ in the off-pump group $(P=.04)$. Causes of in-hospital deaths in the on-pump group were LCOS in 3 patients $(4.6 \%)$ and multiorgan failure in 2 patients $(3 \%)$. In the off-pump group, 1 patient $(1.6 \%)$ died of hepatic failure 6 days after surgery. This patient had a history of severe hepatic failure and arrived in the operating room in cardiogenic shock after an anterior AMI. She underwent CABG with LITA to LAD and a saphenous vein graft to the IVP. The postoperative course was uneventful, and the patient was discharged from the ICU on the second postoperative day with good left ventricle function and in stable hemodynamic condition.

Statistically significant differences were found between the 2 groups concerning the incidence of $\operatorname{LCOS}(P=$ $.001)$, time of mechanical ventilation $(P=.006)$, ICU stay $(P=.01)$, and in-hospital stay $(P=.02)$. Statistically significant differences also were found between the 2 groups concerning the incidence of in-hospital death in patients who were admitted to surgery in cardiac shock $(P=.0018)$ and patients who underwent surgery within 6 hours $(P=$ .0026) from the onset of symptoms (Table 3 ).

\section{Late Outcome}

Patients were followed clinically at the University of Palermo. Follow-up ended between June and December 2007. The mean length of follow-up was $36 \pm 18$ months (range, 2-68 months). No cardiac-related late deaths occurred. No recurrent angina or reintervention (surgery or PCI) was found.

\section{Cardiac Contractile Function}

Transesophageal echocardiography was used to evaluate myocardial contractility in all patients. There was an improvement in the global and regional myocardial kinesia in the off-pump versus on-pump group from the first hour after myocardial revascularization. The values of the wall motion score index in the 2 groups are shown in Figure 1. In the onpump group, the contractile myocardium function was slightly improved after weaning from CPB without a statistically significant difference from the baseline despite successful myocardial revascularization. In the off-pump group, myocardial kinesia was improved at $\mathrm{T} 4$ and $\mathrm{T} 5$ with a statistically significant difference compared with the

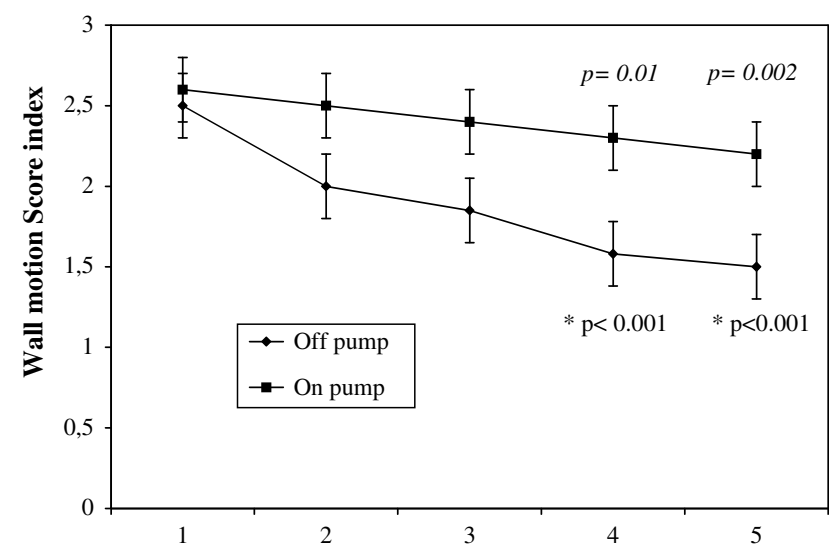

FIGURE 1. Wall motion score index for patients of both groups: time 1 (preoperative), time 2 (30 minutes after the end of myocardial revascularization), time 3 (1 hour after the end of revascularization), time 4 (2 hours after the end of revascularization), and time 5 (4 hours after the end of revascularization). ${ }^{*} P<.001$ in off-pump group compared with baseline.

baseline (T4 vs baseline, $P<.001$; T5 vs baseline, $P<$ .001 ) and the on-pump group (Figure 1).

\section{Serum cTnI Levels}

Preoperative peak maximum serum cTnI levels were not significantly different between the 2 groups. Patients with STEMI who underwent off-pump CABG had significantly lower peak maximum serum cTnI levels compared with those who underwent on-pump CABG.

In all patients, mean cTnI serum levels progressively increased in both groups after myocardial revascularization compared with preoperative values, reaching a peak value at 24 hours after reperfusion. A statistically significant difference was observed between the 2 groups at 12 hours after myocardial revascularization and through the observation period (Figure 2).

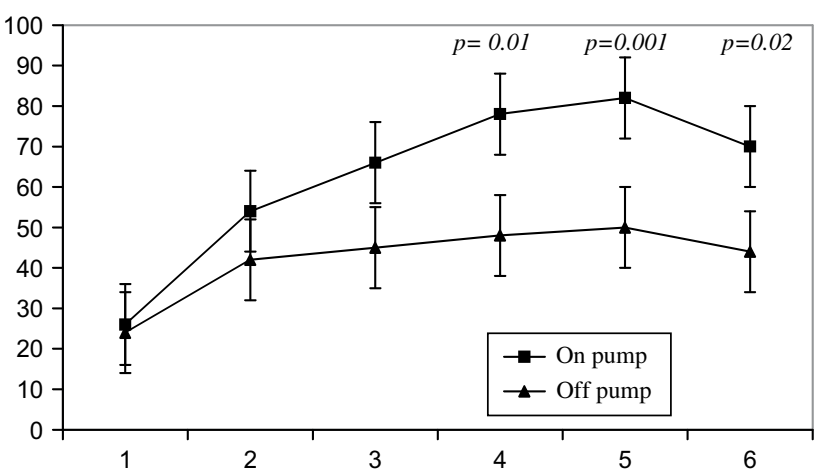

FIGURE 2. Total serum cTnI levels in both groups at the following measurement times: $1=$ preoperative; $2=1$ hour post-revascularization (at the end of all proximal anastomoses); $3=6$ hours post-revascularization, $4=$ 12 hours post-revascularization; $5=24$ hours post-revascularization; and $6=48$ hours post-revascularization. 


\section{DISCUSSION}

Experience with early myocardial surgical revascularization (within the first 6 hours) in patients with evolving AMI began in 1971. DeWood and colleauges ${ }^{9}$ reported hospital mortality rates of $5.2 \%$ and $3 \%$ in patients with Q-wave and non-Q-wave AMI, respectively.

Berg and colleagues ${ }^{10}$ reported an early death rate of $5.5 \%$. In more recent series ${ }^{4-6}$ early mortality from emergency $\mathrm{CABG}$ for AMI remained high and the role of $\mathrm{CABG}$ was controversial. The reasons for this poor result include the poor preoperative status of patients (eg, cardiogenic shock) and myocardial damage after conventional cardioplegic arrest. In 269 consecutive patients with AMI, Sergeant and colleagues ${ }^{11}$ found that CABG had acceptable early and long-term risk in selected patients with evolving myocardial infarction, regardless of their hemodynamic state.

In the past 2 decades, the enthusiasm for emergency CABG in evolving AMI has been diminished with the advent of intravenous thrombolytic therapy and PCI; however, the failure of these measures in several cases and the appearance of post-infarction angina revived the importance of CABG with and without $\mathrm{CPB}$ in the treatment of AMI. The use of beating heart versus conventional cardioplegic cardiac arrest for myocardial revascularization is being intensively debated.

Theoretically, off-pump CABG seems to be an ideal procedure for patients with AMI because it preserves the coronary flow during surgery, avoiding global myocardial ischemia during the cardioplegic arrest period and after ischemia-reperfusion myocardial damage. Moreover, the superiority of the off-pump technique versus conventional CABG in short-term cardiac outcome is well demonstrated by several randomized controlled studies, ${ }^{18,19}$ despite the fact that most of them excluded patients with emergency AMI. The disadvantage of off-pump CABG is the necessity of extreme upward retraction of the heart during revascularization of the circumflex branch, which may be difficult or not applicable in patients with AMI and acute heart failure.

Few reports are available on the postoperative outcomes of off-pump CABG in AMI. In 57 patients who underwent off-pump CABG within the first week of AMI, Mohr and colleagues $^{12}$ found that $\mathrm{CABG}$ without $\mathrm{CPB}$ is a relatively low-risk procedure. In a series of 225 patients who underwent CABG within 7 days of AMI, Locker and colleagues ${ }^{13}$ showed that the early mortality of patients who underwent operation within the first 48 hours with CPB was significantly higher compared with off-pump CABG $(16.5 \%$ vs $4.3 \%, P=.044)$, but the mortality rate in patients who underwent surgery after 48 hours was similar in both groups (5.8\% vs $3.4 \%, P=.44)$. They concluded that $\mathrm{CPB}$ can be used safely for most patients within the first week of AMI, but they advocated avoiding CPB for patients who underwent operation within 48 hours from the onset of symptoms because it was associated with a high operative mortality. Locker and colleagues ${ }^{14}$ also demonstrated that emergency off-pump CABG for AMI results in a lower mortality compared with conventional CABG (5\% vs $24 \%$ ); however, the long-term results of patients without $\mathrm{CPB}$ were no better than those of patients with $\mathrm{CPB}$, which may have been related to the incomplete revascularization or inferior patency rate of anastomoses performed on the beating heart.

Rastan and colleagues ${ }^{15}$ studied 638 consecutive patients with acute coronary syndrome who received emergency CABG (240 patients without CPB and 398 patients with $\mathrm{CPB})$. The authors concluded that the beating heart was associated with an improved hospital outcome and that there were comparable long-term results for high-risk patients presenting with acute coronary syndrome with or without cardiogenic shock.

In our series, the overall in-hospital mortality rate was $4.7 \%$ (6 patients). Five patients $(7.7 \%)$ died in the onpump group and 1 patient $(1.6 \%)$ died in the off-pump group $(P=.04)$. We found that in-hospital mortality was significantly higher in the on-pump versus the off-pump group in patients with preoperative cardiogenic shock $(27 \%$ vs $7.5 \%, P=.0018)$ and in patients who underwent CABG within 6 hours from the onset of AMI $(23 \%$ vs $7.5 \%, P=.0026$ ).

The optimal timing of operation after AMI remains undecided. Several studies report different results. ${ }^{13,14,20,21}$ Locker and colleagues ${ }^{14}$ demonstrated that timing in itself is not a significant predictor of early mortality in off-pump CABG, but it is a significant predictor in patients undergoing operation with $\mathrm{CPB}$. Creswell and colleagues ${ }^{20}$ reported that the mortality rate was $9.1 \%$ in patients undergoing surgery within 6 hours after onset of AMI symptoms, $8.3 \%$ in patients undergoing surgery within 6 hours to 2 days, and $5.2 \%$ in patients undergoing surgery within 2 to 14 days after AMI. In a multicenter analysis, Lee and colleagues ${ }^{21}$ showed that hospital mortality decreased considerably with the increasing time interval between CABG and AMI: $11.8 \%$ for less than 6 hours, $9.5 \%$ for 6 hours to 1 day, and $2.8 \%$ for more than 1 day. In a recent review, Weis and colleagues ${ }^{22}$ reported that patients undergoing CABG within 2 days of hospitalization for AMI experienced higher mortality rates than those undergoing CABG 3 or more days after AMI, independently of clinical acuity, and suggested that CABG may best be deferred for 3 or more days after admission for AMI in nonurgent cases.

In our series, the incidence of early mortality in all patients undergoing operation within 6 hours from the onset of AMI or 6 hours to 2 days was $15.5 \%$ (4/26 patients) and $2 \%(2 / 101$ patients $)$, respectively $(P<.0001)$. In the on-pump group, the incidence of early death in patients 
undergoing operation within 6 hours or more than 6 hours was $23 \%$ (3/13 patients) and 3.8\% (2/52 patients), respectively $(P=.006)$. In the off-pump group, the incidence of early death in patients undergoing operation within 6 hours or more than 6 hours was $7.5 \%$ (1/13 patients) and $0 \%(0 / 49$ patients), respectively. Our results are in agreement with Locker and colleagues ${ }^{14}$ and suggest that the timing of surgery ( $<6$ hours) is a significant predictor of early death in the on-pump group but not in the off-pump group. However, the poor outcome in these patients may depend on factors such as acute left ventricular dysfunction in the early evolving phase of AMI with hemodynamic instability, appearance of post-reperfusion life-threatening arrhythmias, presence of collaterals to ensure coronary runoff after acute occlusion, and fibrinolytic and glycoprotein inhibitor administration that can lead to severe postoperative bleeding, specifically in patients undergoing on-pump CABG. It is fortunate that most patients with AMI are referred to cardiac surgeons after the first 6 hours; however, for patients undergoing emergency operation within 6 hours from the onset of symptoms, we advocate avoiding the use of CPB because it is associated with low in-hospital mortality.

The impact of preoperative cardiogenic shock on early outcome in patients who underwent CABG after AMI is still controversial. Several authors ${ }^{4-7}$ have shown that patients with AMI presenting with cardiogenic shock have poor outcome after CABG. On the other hand, Sergeant and colleauges $^{11}$ and Rastan and colleagues ${ }^{15}$ reported that CABG can be performed with acceptable outcome in patients with evolving AMI, regardless of the preoperative hemodynamic state.

In our series, the incidence of early mortality in patients presenting with cardiogenic shock was $16.5 \%$ (4/24 patients) versus $1.9 \%(2 / 103$ patients $)$ in those without shock $(P<$ $.0001)$. In the on-pump group, the incidence of early death in patients presenting with or without shock was $27 \%$ (3/ 11 patients) and $3.7 \%$ (2/54 patients), respectively $(P=$ .004). In the off-pump group, the incidence of early death in patients presenting with or without preoperative shock was $7.5 \%$ (1/13 patients) and $0 \%$ (0/49 patients), respectively. Our data suggest that preoperative cardiogenic shock increases early mortality after CABG in patients with AMI, specifically in those undergoing on-pump surgery.

In this series, patients who underwent off-pump CABG required less postoperative catecholamine drug administration $(P=.02)$ and time support $(P=.001)$ than patients who underwent on-pump CABG. The incidence of postoperative $\operatorname{LCOS}(P=.001)$ and reoperation for bleeding $(P=.04)$ was significantly higher in the on-pump group versus the off-pump group. Moreover, patients in the on-pump group required more mechanical ventilation time support $(P=.006)$ and longer ICU stay $(P=.01)$ and in-hospital stay $(P=.02)$ than patients in the off-pump group (Table 2). Our data are in agreement with the work of Kerendi and colleagues, ${ }^{16}$ who reported that patients undergoing off-pump surgery received fewer blood transfusions $(65.9 \%$ vs $84.9 \%)$ and had significantly shorter postoperative ICU stays ( 1.47 vs 3.20 days, $P=.016)$ compared with patients undergoing on-pump surgery.

We think that the significant improvement of myocardial contractility (Figure 1) and reduction of postoperative serum cTnI release (Figure 2) in the off-pump group compared with the on-pump group may be attributable to avoiding CPB, since as complete and effective myocardial revascularization was performed in all patients in both groups (measured by intraoperative grafts flow), and all baseline characteristics of the 2 study groups were comparable, without statistically significant difference concerning the preoperative extent of acute myocardial ischemia (measured by preoperative serum levels of cTnI and creatine kinase-MB), left ventricular ejection fraction percentage, wall motion score index, and preoperative clinical presentation was present.

Off-pump CABG is essentially associated with an acute conversion risk, which causes death and serious complications. $^{23-27}$ The conversion risks are difficult to quantify precisely, ${ }^{25}$ and suggested predictors of conversion have included previous $\mathrm{CABG}$, congestive heart failure, AMI, low ejection fraction, and insufficient experience of the surgeon. ${ }^{23,26}$ In other series, ${ }^{27,28}$ the conversion rate was low $(0.4 \%-2.8 \%)$. In our study, the procedure in 1 patient $(1.6 \%)$ in the off-pump group was converted to the onpump beating heart technique during revascularization of the marginal ramus for severe arterial blood hypotension, and $\mathrm{CABG}$ was completed with a good result.

\section{CONCLUSIONS}

Off-pump surgery is the optimal treatment strategy for patients with STEMI, who need urgent CABG. Although $\mathrm{CABG}$ is still associated with a high mortality and morbidity in patients who undergo surgery within the first 6 hours from the onset of symptoms and in those with cardiogenic shock, off-pump surgery shows better results than on-pump surgery. This is supported by the fact that maintaining native coronary blood flow during off-pump surgery avoids global myocardial ischemia, such as during conventional cardioplegic arrest, and post-CPB myocardial cell damage caused by ischemia-reperfusion injury, which can contribute to poor outcome and postoperative left ventricular dysfunction.

\section{References}

1. Grines CL, Browne KF, Marco J, Rothbaum D, Stone GW, O'Keefe J, et al. A comparison of immediate coronary angioplasty with thrombolytic therapy for acute myocardial infarction. $N$ Engl J Med. 1993;328:673-9.

2. Zijlstra F, de Boer MJ, Hoorntje JC, Reiffers S, Reiber JH, Suryapranata H. A comparison of immediate coronary angioplasty with intravenous Streptokinase in acute myocardial infarction. $N$ Engl J Med. 1993;328:680-4.

3. Weaver WD, Simes RJ, Betriu A, Grines CL, Zijlstra F, Garcia E, et al. A comparison of primary coronary angioplasty and intravenous thrombolytic therapy for acute myocardial infarction: a quantitative review. JAMA. 1997;278:2093-8. 
4. Kaul TK, Fields BL, Riggins SL, Dacumos GC, Wyatt DA, Jones CR. Coronary artery bypass grafting within 30 days of an acute myocardial infarction. Ann Thorac Surg. 1995;59:1169-76.

5. Yamagishi I, Sakurada T, Abe T. Emergency coronary artery bypass grafting after acute myocardial infarction. What influences early postoperative mortality? Ann Thorac Cardiovasc Surg. 1998;4:28-33.

6. Wasvary H, Shannon F, Basset J, O’Neill W. Timing of coronary bypass grafting after acute myocardial infarction. Am Surg. 1997;63:710-5.

7. Quigley RL, Milano CA, Smith LR, White WD, Rankin JS, Glower DD. Prognosis an management of anterolateral myocardial infarction in patients with left main disease and cardiogenic shock. The left main shock syndrome. Circulation. 1993; 88(Suppl II):65-70.

8. Eagle KA, Guyton RA, Davidoff R, Edwards FH, Ewy GA, Gardner TJ, et al. ACC/AHA 2004 guideline update for coronary artery bypass graft surgery. A report of the American College of Cardiology/American Heart Association Task Force on Practice Guidelines (Committee to update the 1999 Guidelines for Coronary Artery Bypass Graft Surgery). Circulation. 2004;110:e340-437.

9. DeWood MA, Spores J, Berg R Jr, Kendall RW, Grunwald RP, Selinger SL, et al. Acute myocardial infarction: a decade of experience with surgical reperfusion in 701 patients. Circulation. 1983;68(Suppl II):8-16.

10. Berg R, Kendall RW, Duvoisin GE, Ganji JH, Rudy LW, Everhart FJ. Acute myocardial infarction: a surgical emergency. J Thorac Cardiovasc Surg. 1975;70:432-9.

11. Sergeant $\mathrm{P}, \mathrm{Blackstone} \mathrm{E}, \mathrm{Meyns} B$. Early and late outcome after $\mathrm{CABG}$ in patients with evolving myocardial infarction. Eur J Cardiothorac Surg. 1997;11:848-56.

12. Mohr R, Moshkovitch Y, Shapira I, Amir G, Hod H, Gurevitch J. Coronary artery bypass without cardiopulmonary bypass for patients with acute myocardial infarction. J Thorac Cardiovasc Surg. 1999;118:50-6.

13. Locker C, Mohr R, Paz Y, Kramer A, Lev-ran O, Pevni D, et al. Myocardial revascularization for acute myocardial infarction: benefits and drawbacks of avoiding cardiopulmonary bypass. Ann Thorac Surg. 2003;76:771-7.

14. Locker C, Shapira I, Paz Y, Kramer A, Gurevitch J, Matsa M, et al. Emergency myocardial revascularization for acute myocardial infarction: survival benefit of avoiding cardiopulmonary bypass. Eur J Cardiothorac Surg. 2000;17:234-8.

15. Rastan AJ, Eckenstein JI, Hentschel B, Funkat AK, Gummert JF, Doll N, et al. Emergency coronary artery bypass graft surgery for acute coronary syndrome. Beating heart versus conventional cardioplegic cardiac arrest strategies. Circulation. 2006;114(Suppl I):477-85.

16. Kerendi F, Puskas JD, Craver J, Cooper WA, Jones EL, Lattouf O, et al. Emergency coronary artery bypass grafting can be performed safely without cardiopulmonary bypass in selected patients. Ann Thorac Surg. 2005;79:801-6.

17. Schiller NB, Shan PM, Crawford M, De Maria A, Devereux R, Feigenbaum H, et al. Recommendations for quantitation of the left ventricle by two-dimensional echocardiography. American society of echocardiography committee on standards, subcommittee on quantitation of two dimensional echocardiograms. $J$ Am Echocardiogr. 1989;2:358-67.

18. Van DijK, Nierich AP, Jansen EW, Nathoe HM, Suyker WJ, Diephuis JC, et al. Early outcome after off-pump versus on-pump coronary bypass surgery: results from a randomised study. Circulation. 2001;104:1761-6.

19. Khan NE, De Souza A, Mister R, Flather M, Clague J, Davies S, et al. A randomized comparison of off-pump and on-pump multivessel coronary artery bypass surgery. N Engl J Med. 2004;350:21-8.

20. Creswell LL, Moulton MJ, Cox AL, Rosenbloom M. Revascularization after acute myocardial infarction. Ann Thorac Surg. 1995;60:19-26.

21. Lee DC, Oz MC, Weiberg AD, Lin SX, Ting W. Optimal timing of revascularization: transmural versus nontransmural acute myocardial infarction. Ann Thorac Surg. 2001;71:1198-204.

22. Weis ES, Chang D, Joyce D, Nwakanma LU, Yuh DD. Optimal timing of coronary artery bypass after acute myocardial infarction. A review of California discharge data. J Thorac Cardiovasc Surg. 2008;135:503-11.

23. Edgerton JR, Dewey TM, Magee MJ, Herbert MA, Prince SL, Jones KK, et al. Conversion in off-pump coronary artery bypass grafting: an analysis of predictors and outcomes. Ann Thorac Surg. 2003;76:1138-43.

24. Légaré JF, Buth KJ, Hirsch GM. Conversion to on pump from OPCAB is associated with increased mortality: results from a randomised controlled trial. Eur $J$ Cardiothorac Surg. 2005;27:296-301.

25. Reeves BC, Ascione R, Caputo M, Angelini GD. Morbidity and mortality following acute conversion from off-pump to on-pump coronary surgery. Eur J Cardiothorac Surg. 2006;29:941-7.

26. Vassiliades TA Jr, Nielsen JL, Lonquist JL. Hemodynamic collapse during off-pump coronary artery bypass grafting. Ann Thorac Surg. 2002;73: 1874-9.
27. Hart JC, Spooner TH, Pym J, Flavin TF, Edgerton JR, Mack ML, et al. A review of 1,582 consecutive octopus off-pump coronary bypass patients. Ann Thorac Surg. 2000;70:1017-20.

28. Anyanwu AC, A.L. -Ruzzeh, George SJ, Patel R, Yacoub MH, Amrani M. Conversion of off-pump coronary by-pass without increased morbidity or change in practice. Ann Thorac Surg. 2002;73:79-802.

\section{Discussion}

Dr T. Sundt (Rochester, Minn). I congratulate the authors on doing this study. A prospectively randomized study isn't an easy thing to do. I guess I should add that my only conflict of interest is that I have less concern about the controversy over on-pump versus offpump than I have about the use of arterial grafts. I think as a group, cardiac surgeons would have done well to put more of our energy into understanding the role of arterial grafts.

Nonetheless, the controversy over off-pump surgery continues, and this is an important article. The fact that the controversy continues begs the question "Why is it that after over a decade of exploring this matter, the adoption of off-pump surgery is still pretty modest?', Today, only approximately $20 \%$ of coronary revascularizations are done off-pump despite multiple retrospective studies that have suggested a benefit to eliminating the pump. Why is that? Part of the answer is that most of the randomized studies performed thus far have demonstrated a relatively modest advantage to the off-pump strategy, including little neurocognitive benefit and a modest mortality benefit if any at all. The advocates of the offpump approach point to reductions in blood transfusion requirements and ICU length of stay, but up to now, little has been shown with regard to the outcome that most grabs our attention: mortality. The reason for this disconnect between retrospective and prospective studies on this subject is the same as the reason that it is difficult to show a difference in mortality rate between PCI and coronary bypass. As David Taggert has argued vehemently, it is the low-risk patients who are entered into the randomized studies, and if lowrisk patients are entered into randomized studies, you are unlikely to see a mortality benefit regardless of what you do! So I congratulate you in particular in taking the necessary step in entering the high-risk patients. They are indeed the ones in whom we might expect to see a difference in mortality, and you have successfully demonstrated that. This is an important step.

With those comments, I have just a couple of questions. It is a well-written and beautifully presented article. One question is in regard to the randomization process. Were the same surgeons doing the on-pump and off-pump cases? If they were not, then it could be that more skilled surgeons were doing the off-pump cases than the on-pump cases, and in fact we are looking at a surrogate for surgical skill.

Dr Fattouch. This work is part of our experience in the high-risk patients with STEMI who underwent CABG at our institution. We started this experience at the University of Palermo in 2002, and since the beginning of our experience, in collaboration with interventional cardiologists in the West Sicily district, we aimed to treat these patients. Encouraged by our initial results obtained with offpump CABG, we designed this randomized study to evaluate the effects of off-pump versus on-pump CABG in high-risk patients with STEMI who underwent $C A B G$ in the early phase. We started this study because our opinion about the superiority of off-pump CABG in patients with STEMI is supported by the fact that avoiding $\mathrm{CPB}$, and not only the conventional cardioplegic arrest, leads to 
less activation on the inflammatory cascade and less deposit into the microvasculature of monomorphonuclear cells, which have an important role in postoperative reperfusion/ischemia damage. Moreover, the postoperative improvement of myocardial function that was observed in the patients who underwent off-pump surgery is due to the fact that in on-pump surgery the heart is empty and in an empty heart the left ventricular wall geometry change leads to impedance of coronary collateral flow supplying ischemic areas of myocardium. The patency of these collaterals is important in these patients to limit the extension of the area of ischemic myocardial damage. Moreover, it has been shown that normal interventricular septum movement is better preserved after off-pump surgery, which improves LV function. Finally, we have a team dedicated for this type of surgery, and all cases were done by the same team of surgeons with high expertise in coronary artery surgery and specifically in off-pump CABG.

Dr Sundt. A second question would be about the number of grafts per patient. They are clearly similar between both groups but rather modest, less than 3 grafts per patient in both cases. Do you have data about the number of diseased vessels and completeness of revascularization, or is the low number of grafts a reflection of the patients' extremis? Do you tend to minimize the number of grafts in these patients? Is this a low number for you?

Dr Fattouch. In our series, the mean number of grafts per patient was 2.8 in the on-pump group and 2.6 in the off-pump group; they are clearly similar between both groups without a statistically significant difference. So, I agree with you that less than 3 grafts per patient could seem modest but reflects honestly what we observed. In these high-risk patients with STEMI, sometimes with cardiac shock, life-threatening arrhythmias, and multivessel disease, our policy was to perform complete myocardial revascularization.

Dr Sundt. Do you know what percentage of patients with AMI from your network wound up coming to the operating room? We just don't see it very often. It is uncommon for us to see a patient in the operating room with an AMI. Most of them are rescued in the catheter laboratory.

Dr Fattouch. The overall incidence of patients with STEMI who need early urgent or emergency CABG is approximately $3 \%$ to $4 \%$ among all patients who have an AMI. To answer the second part of your question, I think that we observed this high number of patients at our institution because we have a district network for the treatment of these patients in collaboration with cardiologists working in several coronary ICUs and catheter laboratories since 2002. So, in our institution we operated on more than 300 patients in the evolving phase of STEMI, and the results are acceptable.

Dr P. Kurlansky (Miami, Fla). I also congratulate you on conducting an extremely difficult study. The use of cardioplegic arrest not only provides the opportunity for operating in a silent, bloodless field but also provides the opportunity for substrate enhancement, which may be particularly relevant to this particular group of patients who are acutely ischemic. In your experience or in the study, was anything done specifically to alter the mechanisms or methodology of cardioplegia to provide specific substrate enhancement for this particularly ill group of patients.?

Dr Fattouch. I think that off-pump CABG is better and superior to on-pump in these patients because by using an intracoronary shunt, you can conserve the native blood flow and the opportunity to supply substrate to the ischemic myocardium. However, in the case of occluded vessel, I think that a delay for 10 minutes in the beating heart, the time we need to put the graft and supply blood flow, is not an additional risk factor for ischemic myocardium. So, it is evident that in this case we must first address the occluded guilty vessel. Finally, in patients undergoing on-pump CABG, we use blood cardioplegia under a normothermic $\mathrm{CPB}$, which is the best option, in our opinion. Currently, we avoid the use of $\mathrm{CPB}$ for all of the reasons that I have discussed with Dr Sundt. 